\title{
Efficacy Analysis of an Experience on Development of the Combination Therapy Protocol for Endometriosis Management
}

\author{
Abo Taleb Saremi1 ${ }^{*}$, Ameneh Lahooti Eshkevari², Katayoun Esmaili Pour², Arash Pooladi1 \\ ${ }^{1}$ Sarem Fertility \& Infertility Research Center (SAFIR) \& Sarem Cell Research Center (SCRC), Sarem Women's Hospital, Tehran, Iran \\ ${ }^{2}$ Infertility Department, Sarem Women’s Hospital, Tehran, Iran \\ Email: *Saremiat@yahoo.com
}

How to cite this paper: Saremi, A.T., Eshkevari, A.L., Pour, K.E. and Pooladi, A. (2017) Efficacy Analysis of an Experience on Development of the Combination Therapy Protocol for Endometriosis Management. Open Journal of Obstetrics and Gynecology, 7, 31-40.

http://dx.doi.org/10.4236/ojog.2017.71004

Received: October 27, 2016

Accepted: December 20, 2016

Published: December 23, 2016

Copyright $\odot 2017$ by authors and Scientific Research Publishing Inc. This work is licensed under the Creative Commons Attribution International License (CC BY 4.0).

http://creativecommons.org/licenses/by/4.0/

\section{Abstract}

Purpose: Endometriosis can be managed effectively by medication, surgery, or a combination of both. Numerous studies have been conducted on surgical and medication treatment options, but their results are still under discussion. Therefore, we performed a study to develop a combinational treatment for various stages of endometriosis. Methods: Over a 3-year period, 218 documented endometriosis patients were classified in 4 stages. After first laparoscopy (with electrocoagulation and adhesion removal for stages I to III), the patients were treated with $\mathrm{GnRH}$ analogs (Gonadotropin Releasing Hormone Agonist-375 mg of Decapeptyl) for 3, 6 \& 6 months, respectively. The second and third laparoscopy procedures were performed after 3 and 6 months, with add-back therapy. The treatment was evaluated by direct observation based on laparoscopic view and the pain relief was measured by the VAS (Visual Analogue Scale) after the first step of medication for patients of stages I-III. Results: After 3 months, 70/76 patients (91.9\%) with stage-I endometriosis showed complete recovery (six cases after 6 months) while 65/72 and 32/43 cases with stage-II and -III (90.3 and 74.4\%), respectively, showed complete recovery after 6 months of treatment. The remaining patients had $\mathrm{GnRH}$ treatment for another 3 months, and all showed a complete recovery after 9 months. Furthermore, 12 of the patients with stage-IV symptoms were candidates for laparoscopy or laparotomy, and their treatment response rate was $55.6 \%$. The pain relief was significant after the combinational treatment in patients with stages I-III $(P=0.0001)$. Conclusion: Our study showed efficacy of the developed protocol for the endometriosis management.

\section{Keywords}

Endometriosis, Combinational Therapy, Management, Protocol Development, Efficacy 


\section{Introduction}

The presence of stromal endometrial glands outside the uterus is the classic definition of endometriosis. Endometriosis is a chronic gynecological disorder that commonly manifests as dysmenorrhea, chronic pelvic pain, and infertility. It is one of the most prevalent diseases in women of reproductive age worldwide, as well as the third leading cause of hospitalization in women [1] [2] and one of the main reasons for hysterectomies [3]. The exact prevalence of endometriosis is not known, but its estimated and reported range in previous studies is from $2 \%$ to $10 \%$ in women of reproductive age [4] [5], $38 \%$ to $50 \%$ in infertile women [6] [7], and up to $87 \%$ in women with chronic pelvic pain [7]. Therefore, it appears that the effective treatment of this disabling condition is necessary and should be a priority before the initiation of assisted reproductive treatment for infertile and subfertile women [8].

Endometriosis may be managed with medication, surgical treatment, or the combination of both strategies. Previous studies have been conducted on surgical and medication-based treatments, but these strategies require additional development to enhance their efficacy [9] [10]. Laparoscopy is accepted as the diagnostic gold standard and one of the main treatment methods for endometriosis [11] [12] [13] [14]. While medications could be effective following the removal of endometrial lesions [15] [16], no explanation exists for the ineffectiveness of medication treatment before endometriosis cysts or spots are removed [16] [17] [18] [19]. The need for drug treatment after laparoscopy has also been indicated by previous studies [20] [21] [22], and the use of 6-month gonadotropin-releasing hormone ( $\mathrm{GnRH})$ agonist therapy following laparoscopy prevented endometriosis recurrence [23]. Presently, new endometriosis treatment strategies are required and should be developed. Therefore, we conducted a study to develop a combinational treatment approach by determining the appropriate intervals for treatment assessment and surveying the efficiency of this approach. Specifically, we used direct observation with laparoscopy at various stages of documented endometriosis and assessed the pain relief provided to female patients of reproductive age.

\section{Material \& Methods}

This was a non-experimental interventional study conducted with 218 patient volunteers from Sarem Women's Hospital Endometriosis Clinic from April 2013 to January 2016. The patients had documented endometriosis and were unresponsive to oral contraceptive pill (OCP). Patients with colorectal or bladder invasion of endometriosis or both were excluded from the study. The Hospital Ethical Committee approved the study with approval letter No. 8909-877. The patients were completely informed about the treatment procedures and provided an informed signed consent form. Then, the patients commenced the study and were treated using our designed treatment protocol, which was followed by a second and third observational laparoscopy for advanced stages of endometriosis. The treatment protocol was successfully piloted in 2012 with 47 patients and has been improved in this study using a greater sample size.

In the first laparoscopic procedure, the endometriosis was diagnosed, and the stage was defined based on the revised American Society for Reproductive Medicine (ASRM) classification of endometriosis [24]. Based on this procedure, the patients were classi- 
fied into four stages (I-IV) of endometriosis with the supervision and observation of the Chief Surgeon.

Our treatment protocol design included the use of a GnRH agonist to loosen the endometriosis lesions; then, we allowed the appropriate period to elapse (3-month interval). Then, we evaluated the condition by direct observation to determine the requirement for further minimal invasive surgical procedures such as electrocoagulation, dissections, adhesion removal, and cyst excision (this recent option performed only for endometrioma cysts) based on the existing guidelines and recommendations [25]-[30]. The endometrioma cysts were also confirmed based on tissue diagnosis. It is noteworthy that in the first laparoscopy, the surgical intervention was performed for all the patients except those in stage-IV. No surgical intervention was performed in stage-IV because this was postponed until after the second observation following the 9-month GnRH agonist treatment. The $375 \mathrm{mg}$ dose of decapeptyl (triptorelin) as the GnRH analog was injected monthly, and the first medication duration was set as follows based on our previous experience in the pilot study:

- 3 months for stage-I.

- 6 months for stage-II and III.

- 9 months for stage-IV.

The medication duration was 3 months longer in each subsequent stage when necessary based on the additional laparoscopy. The thirdobservational laparoscopy procedures were needed for stage-III and -IV patients. The add-back therapy (OCP) was initiated for patients who were candidates for a longer than 6-month GnRH agonist therapy [31]. The study scheme of the surgical-medical protocol development for this endometriosis treatment is illustrated in Figure 1. As it mentioned before, the treatment was evaluated by patients' symptoms and the direct observation based on

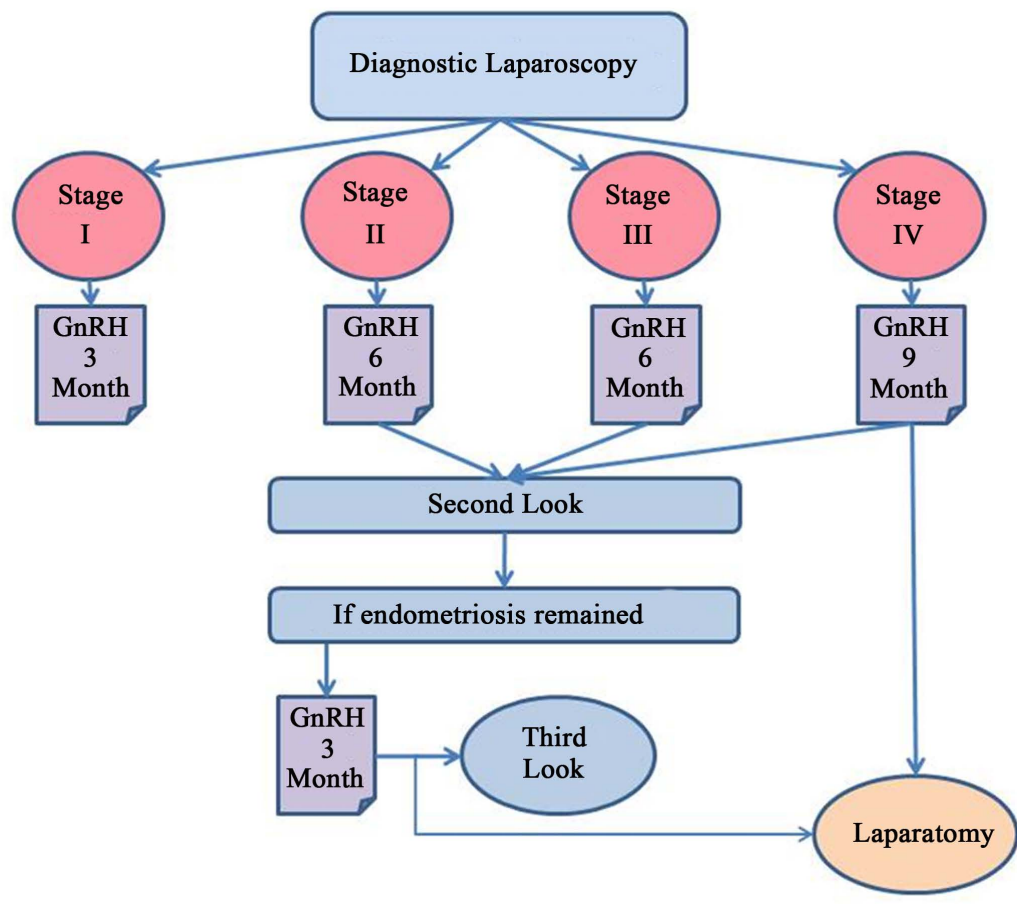

Figure 1. The study management protocol. 
laparoscopic view as the chief surgeon rate the condition based on ASRM checklist for classification of endometriosis. So, any changes involving the reduction, curing or increasing of the endometriosis were recorded. For patients with ethical limitation for further laparoscopic procedure (like the stage-I patients for second look laparoscopy), only clinical symptoms were the criteria for the patient curing. Accordingly, the pain relief was measured by the VAS (Visual Analogue Scale) after the first step of medication and before the last laparoscopy for patients of stages I-III (In Stage-I after 3 months, Stage-II \& -III after 6 months patients rate their pain from 1 to 10). The VAS is a simple tool like a ruler for visualizing and quantifying of the pain severity that perform by the patients themselves.

The data were analyzed by SPSS software V.23 using descriptive statistics and paired $\mathrm{t}$-test as the analytical statistical test.

\section{Results}

In this study among the 218 patients, 76, 72, 43, and 27 (34.9\%, 33\%, 19.7\%, and 12.4\%) were in stage-I, -II, -II, and -IV, respectively. The mean age and body mass index (BMI) of the patients was $31.11 \pm 4.69$ years and $24.30 \pm 3.79$, respectively. These data and the symptom frequencies are shown in Table 1.

The results of the endometriosis management revealed that $83.5 \%$ of all patients and $87.43 \%$ of those with stage I-III were cured by the first step of the therapeutic method, which increased to $93.6 \%$ of all patients after the initiation of the second step of the protocol. The protocol was beneficial in relieving the pain of $77.52 \%$ of patients. Pain relief significantly decreases after the initial treatment step of the protocol $(P=0.0001$, Figure 2). Interestingly, the visceral endometriosis symptoms were cured following the drug therapy phase of the protocol. As it show in Table 2, at the stage-I of endometriosis $91.9 \%$ of the patients were cured after 3 months GnRH agonist treatment (data was based on their clinical symptoms) and $90.3 \%$ of Stage-II patients were cured after 6 months medication after initial laparoscopy. Continuing the medication for further 3 months relief the symptoms for all of the remained patients with stage-I \& -II of endometriosis. Initial laparoscopy with 6 months medication is curable for $74.4 \%$ of the

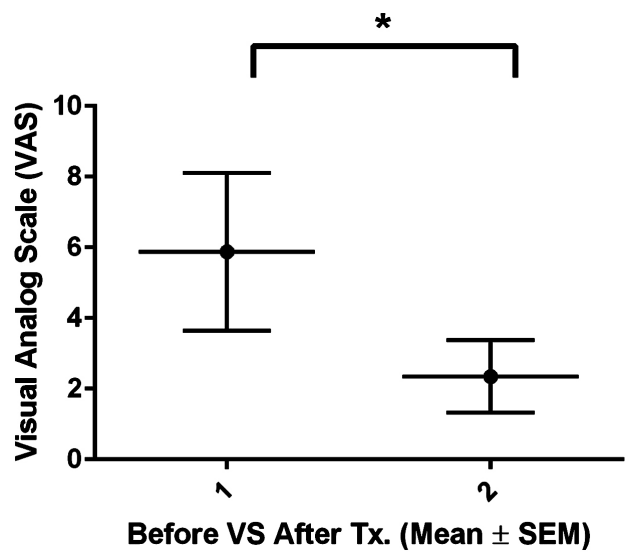

Figure 2. Pain relief assessment using visual analogue scale (VAS) for patients with endometriosis after initial combinational treatment protocol. ${ }^{\star}$ Paired T-test; t: $21.354, \mathrm{df:} 217, P$-value: 0.0001 . 
Table 1. Distribution of patients by endometriosis stage, age, body mass index (BMI), and symptoms.

\begin{tabular}{cccccc}
\hline \multirow{2}{*}{ Endometriosis stage } & Frequency (\%) & Age mean \pm SD & BMI mean \pm SD & \multicolumn{2}{c}{ Symptoms/presentations } \\
\cline { 5 - 6 } Stage I & $76(34.9)$ & $30.88 \pm 4.39$ & $25.13 \pm 3.66$ & $57(26.15)$ & Dysmenorrhea \\
Stage II & $72(33.0)$ & $30.70 \pm 4.96$ & $24.43 \pm 3.78$ & $56(25.69)$ & $9(4.13)$ \\
Stage II & $43(19.7)$ & $31.07 \pm 4.82$ & $22.56 \pm 3.52$ & $29(13.3)$ & $6(2.75)$ \\
Stage IV & $27(12.4)$ & $32.96 \pm 4.31$ & $24.27 \pm 3.96$ & $22(10.09)$ & $9(4.13)$ \\
Total & $218(100)$ & $31.11 \pm 4.69$ & $24.30 \pm 3.79$ & $164(75.23)$ & $37(16.97)$ \\
\hline
\end{tabular}

Table 2. Outcome of patients with endometriosis after combinational treatment protocol.

\begin{tabular}{|c|c|c|c|c|c|c|c|c|c|}
\hline \multirow[b]{2}{*}{$\begin{array}{l}\text { Endomet-riosis } \\
\text { stage }\end{array}$} & \multirow[b]{2}{*}{ Frequency } & \multirow[b]{2}{*}{$\begin{array}{c}\text { Initial } \\
\text { procedures }\end{array}$} & \multirow{2}{*}{$\begin{array}{c}\text { Cured } \\
\text { personswith } \\
\text { initial procedures }\end{array}$} & \multirow{2}{*}{$\begin{array}{l}\text { Cured } \\
\text { persons } \\
\text { after more } \\
\text { GnRH Tx. }\end{array}$} & \multicolumn{2}{|c|}{ Laparoscopy } & \multirow{2}{*}{$\begin{array}{l}\text { Symptoms } \\
\text { reduction/pain } \\
\text { relief after } \\
\text { Initial } \\
\text { procedures }\end{array}$} & \multirow{2}{*}{$\begin{array}{c}\text { Cure } \\
\text { based } \\
\text { on: }\end{array}$} & \multirow{2}{*}{$\begin{array}{l}\text { Relapse } \\
\text { after } \\
1 \text { year }\end{array}$} \\
\hline & & & & & $\begin{array}{c}\text { Second } \\
\text { observation }\end{array}$ & $\begin{array}{c}\text { Third } \\
\text { observation }\end{array}$ & & & \\
\hline Stage I & 76 & $\begin{array}{l}\text { Lap.Tx + GnRH } \\
\text { for } 3 \text { months }\end{array}$ & 70 (91.9\%) & $\begin{array}{l}6(8.1 \%) \\
(6 \text { persons } \\
\text { cure after } \\
\text { another } \\
\text { 3-months } \\
\text { GnRH) }\end{array}$ & 0 & 0 & $\begin{array}{c}70 \\
(91.9 \%)\end{array}$ & $\begin{array}{l}\text { Only } \\
\text { patients } \\
\text { with pain } \\
\text { relief }\end{array}$ & $\begin{array}{c}8 \\
(10.5 \%)\end{array}$ \\
\hline Stage II & 72 & $\begin{array}{l}\text { Lap. } \mathrm{Tx}+\mathrm{GnRH} \\
\text { for } 6 \text { months }\end{array}$ & $65(90.3 \%)$ & $\begin{array}{l}7(9.7 \%) \\
(7 \text { persons } \\
\text { cure after } \\
\text { another } \\
\text { 3-months } \\
\text { GnRH) }\end{array}$ & 7 & 0 & $\begin{array}{c}61 \\
(84.72 \%)\end{array}$ & $\begin{array}{l}\text { Lap. direct } \\
\text { observation } \\
\text { followed by } \\
\text { pain relief }\end{array}$ & $\begin{array}{c}16 \\
(22.2 \%)\end{array}$ \\
\hline Stage II & 43 & $\begin{array}{l}\text { Lap. } \mathrm{Tx}+\mathrm{GnRH} \\
\text { for } 6 \text { months }\end{array}$ & $32(74.4 \%)$ & $\begin{array}{l}11(25.6 \%) \\
\text { (9 persons } \\
\text { cure after } \\
\text { another } \\
\text { 3-month } \\
\text { GnRH } \\
\text { treatment) }\end{array}$ & 11 & 2 & $\begin{array}{c}28 \\
(65.11 \%)\end{array}$ & $\begin{array}{l}\text { Lap. direct } \\
\text { observation }\end{array}$ & $\begin{array}{c}10 \\
(23.3 \%)\end{array}$ \\
\hline Stage IV & 27 & $\begin{array}{c}\text { Dx Lap. }+ \text { GnRH } \\
\text { for } 9 \text { months } \\
+ \text { second } \\
\text { observation } \\
\text { Lap.Tx }\end{array}$ & $15(55.6 \%)$ & $\begin{array}{l}- \\
\text { (After 3rd } \\
\text { Look Lap., all } \\
\text { remained } 12 \\
\text { persons } \\
\text { candidate for } \\
\text { Laparotomy) }\end{array}$ & 27 & 27 & $\begin{array}{c}10 \\
(37.04 \%)\end{array}$ & $\begin{array}{l}\text { Lap. direct } \\
\text { observation } \\
\text { and then Lap. }\end{array}$ & $\begin{array}{c}13 \\
(48.1 \%)\end{array}$ \\
\hline Total & $218(100 \%)$ & - & $\begin{array}{r}\text { Cured by } \\
\text { procedure }=1 \\
\text { Total cured by } \\
\text { third observation } \\
\text { GnRH }=204\end{array}$ & $\begin{array}{l}\text { above } \\
82(83.5 \%) \\
\text { second and } \\
\text { and additional } \\
4(93.6 \%)\end{array}$ & $\begin{array}{c}45 \\
(20.64 \%)\end{array}$ & $\begin{array}{c}29 \\
(13.3 \%)\end{array}$ & $\begin{array}{c}169 \\
(77.52 \%)\end{array}$ & - & $\begin{array}{c}47 \\
(21.6 \%)\end{array}$ \\
\hline
\end{tabular}

GnRH, gonadotropin-releasing hormone; Tx, treatment; Lap., laparoscopy.

patients with stage-IV. Further 3 months medication could reach this rate to $95.3 \%$. The curative rate of the combinational therapy in the stage-IV was $55.6 \%$ in the first 
step of the protocol. It must be note that, the process was different in the stage-IV and the initial laparoscopy was only diagnostic and not any procedure for adhesion removal nor other manipulation had been done. The long medication duration for 9 months performed and in the second laparoscopy the adhesions had been removed and spots been electro-cauterized.

Relapse of the endometriosis is common phenomenon that increases by the severity of the disease. Overall relapse rate of the patients in this study was $21.6 \%$. The relapse rates in the stage I to IV were $10.5 \%, 22.2 \%, 23.3 \% \& 48.1 \%$ respectively.

It is worth mentioning that only menopausal symptoms (such as hot flushes, sleep disturbance, mood swings, and amenorrhea) were observed in patients during the medical treatment phase. There were no reports of any other symptoms, complications, or complaints during our follow-up.

\section{Discussion}

This investigational protocol consists of consecutive laparoscopies and time-managed injections of $\mathrm{GnRH}$ agonist with a minimally invasive surgical procedure. Furthermore, the treatment duration of the GnRH agonist injection varies between 3 - 12 months depending on the stage of endometriosis. No medical drug treatment was initiated before surgery in our survey because laparoscopy is the gold standard for endometriosis diagnosis, especially in early stages of endometriosis [32] [33]. Although laparoscopy is a definite treatment for endometriomas, the current guidelines for endometriosis removal vary with different approaches [34] [35]. For instance, radical operations on the urinary tract or bowel excision and the resulting inflammatory reactions are the most harmful side effects, which may also cause additional adhesions and endometriosis recurrence themselves. Therefore, some studies suggest avoiding these kinds of operations in endometriosis treatment [35] [36].

The surgical approach in our protocol was a laparoscopic procedure aimed at minimizing the disease symptoms in reproductive organs without any radical manipulations, especially in the visceral organs or bladder. Furthermore, the endometrioma fibrotic capsules were completely drained and extirpated from the ovarian tissue in all cases and because of the risk of ovarian tissue damage with very large endometriomas [37]. The remaining ovarian tissue was sutured to enhance its aggregation [38]. The 3-month GnRH agonist treatment was inadequate for stage III and IV endometriosis [39], and the beneficial effect of a 6-month course of GnRH agonist treatment after laparoscopy [40] was demonstrated. This was evident from the results showing that the subsequent time-managed medical phase of our advanced protocol, which includes various periods of $\mathrm{GnRH}$ analog injection after the laparoscopy (depending on endometriosis stage), adequately compensated for the laparoscopic shortcomings based on the high cure rate of the patients.

Interestingly, the symptoms of infiltrative bowel or visceral endometriosis were totally eliminated by the medical drug treatment alone, which was further confirmed by the clinical examinations and the second or third laparoscopic observations. Therefore, as previously recommended, [8] [41], the administration of a $\mathrm{GnRH}$ agonist after laparoscopic surgery should be considered as an important part of the endometriosis cura- 
tive therapy strategy and recurrence prevention. Consequently, this study demonstrated that compared to all other existing methods, our developed surgical-medical protocol has an acceptable rate of endometriosis removal (93.6\%). Therefore, it would be a valuable method for curing endometriosis and preventing its recurrence, particularly for patients who desire to conceive and are referred to an infertility clinic. In addition, we advise patients who do not desire to conceive to take prolonged OCP therapy. Our results also suggest that this advanced method of early definitive diagnosis of endometriosis by performing laparoscopy instead of blindly administering initial medical and drug therapies would be a clinical advancement for endometriosis treatment and related infertility.

In this study we were facing some practical and ethical limitations like the needs for follow-up of the patients, commitment of the patients to the treatment protocol \& restriction about the second laparoscopic view in patients with stage-I and third look for patients with stage-II for direct observation as a reliable method for detecting curing the endometriosis lesions.

\section{Conclusion}

Our present study proved that the severe stage of endometriosis required aggressive and longer treatment duration than the earlier stages did. In addition, we demonstrated that the patients in stage IV required a very complicated treatment regimen of 9 months of decapeptyl injections and extensive laparoscopy or laparotomy surgery. In stage I, we recommended the use of a 3-month course of decapeptyl injections in addition to cauterizing the endometriosis spots using electrocoagulation to achieve a complete recovery. In stages II and III, after the laparoscopy surgery, decapeptyl was injected for 6 months, and the prescription of the new dosage was dependent on the second observational laparoscopy following this period. However, the selection of the best treatment strategy for patients with endometriosis and infertility issues requires additional research and discussion.

\section{Acknowledgements}

Special thanks to our colleagues in Sarem Women's Hospital \& Sarem Research Centers (SAFIR \& SCRC).

\section{References}

[1] Velebil, P., Wingo, P.A., Xia, Z., Wilcox, L.S. and Peterson, H.B. (1995) Rate of Hospitalization for Gynecologic Disorders among Reproductive-Age Women in the United States. $\mathrm{Ob}$ stetrics \& Gynecology, 86, 764-769. https://doi.org/10.1016/0029-7844(95)00252-M

[2] Whiteman, M.K., Kuklina, E., Jamieson, D.J., Hillis, S.D. and Marchbanks, P.A. (2010) Inpatient Hospitalization for Gynecologic Disorders in the United States. American Journal of Obstetrics \& Gynecology, 202, 541-546. https://doi.org/10.1016/j.ajog.2009.12.013

[3] Mounsey, A.L., Wilgus, A. and Slawson, D.C. (2006) Diagnosis and Management of Endometriosis. American Family Physician, 74, 594-600.

[4] Eskenazi, B. and Warner, M.L. (1997) Epidemiology of Endometriosis. Obstetrics \& Gynecology Clinics of North America, 24, 235-258.

https://doi.org/10.1016/S0889-8545(05)70302-8 
[5] (2010) Practice Bulletin No. 114: Management of Endometriosis. Obstetrics \& Gynecology, 116, 223-236. https://doi.org/10.1097/AOG.0b013e3181e8b073

[6] Meuleman, C., Vandenabeele, B., Fieuws, S., Spiessens, C., Timmerman, D. and D’Hooghe, T. (2009) High Prevalence of Endometriosis in Infertile Women with Normal Ovulation and Normospermic Partners. Fertility and Sterility, 92, 68-74. https://doi.org/10.1016/j.fertnstert.2008.04.056

[7] Armstrong, C. (2011) Acog Updates Guideline on Diagnosis and Treatment of Endometriosis. In: AMER ACAD FAMILY PHYSICIANS 8880 WARD PARKWAY, KANSAS CITY, MO 64114-2797 USA.

[8] Saremi, A. (2000) Treatment of Endometriosis as a Priority before Art. International Journal of Gynecology \& Obstetrics, 70, A49. https://doi.org/10.1016/s0020-7292(00)82133-5

[9] Roman, H. (2007) Guidelines for the Management of Painful Endometriosis. Journal de Gynécologie Obstétrique et Biologie de la Reproduction (Paris), 36, 141-150. https://doi.org/10.1016/j.jgyn.2006.12.008

[10] Leyland, N., Casper, R., Laberge, P., Singh, S.S., et al. (2010) Endometriosis: Diagnosis and Management. Journal of Obstetrics and Gynaecology Canada, 32, S1-S32. https://doi.org/10.1016/s1701-2163(16)34589-3

[11] Rodgers, A.K. and Falcone, T. (2008) Treatment Strategies for Endometriosis. Expert Opinion on Pharmacotherapy, 9, 243-255. https://doi.org/10.1517/14656566.9.2.243

[12] Muzii, L., Bellati, F., Bianchi, A., Palaia, I., Manci, N., Zullo, M.A., et al. (2005) Laparoscopic Stripping of Endometriomas: A Randomized Trial on Different Surgical Techniques. Part Ii: Pathological Results. Human Reproduction, 20, 1987-1992. https://doi.org/10.1093/humrep/deh851

[13] Dunselman, G.A., Vermeulen, N., Becker, C., Calhaz-Jorge, C., D’Hooghe, T., De Bie, B., et al. (2014) Eshre Guideline: Management of Women with Endometriosis. Human Reproduction, 29, 400-412. https://doi.org/10.1093/humrep/det457

[14] Wykes, C.B., Clark, T.J. and Khan, K.S. (2004) Accuracy of Laparoscopy in the Diagnosis of Endometriosis: A Systematic Quantitative Review. BJOG, 111, 1204-1212. https://doi.org/10.1111/j.1471-0528.2004.00433.x

[15] Vercellini, P., Trespidi, L., Colombo, A., Vendola, N., Marchini, M. and Crosignani, P.G. (1993) A Gonadotropin-Releasing Hormone Agonist versus a Low-Dose Oral Contraceptive for Pelvic Pain Associated with Endometriosis. Fertility Sterility, 60, 75-79. https://doi.org/10.1016/S0015-0282(16)56039-7

[16] Brown, J., Pan, A. and Hart, R.J. (2010) Gonadotrophin-Releasing Hormone Analogues for Pain Associated with Endometriosis. Cochrane Database of Systematic Reviews, 2010, CD008475.

[17] Hornstein, M.D., Hemmings, R., Yuzpe, A.A. and Leroy Heinrichs, W. (1997) Use of Nafarelin versus Placebo after Reductive Laparoscopic Surgery for Endometriosis. Fertility and Sterility, 68, 860-864. https://doi.org/10.1016/S0015-0282(97)00360-9

[18] Hornstein, M.D., Yuzpe, A.A., Burry, K.A., Heinrichs, L.R., Buttram Jr., V.L. and Orwoll, E.S. (1995) Prospective Randomized Double-Blind Trial of 3 versus 6 Months of Nafarelin Therapy for Endometriosis Associated Pelvic Pain. Fertility and Sterility, 63, 955-962. https://doi.org/10.1016/S0015-0282(16)57530-X

[19] Yap, C., Furness, S. and Farquhar, C. (2004) Pre and Post Operative Medical Therapy for Endometriosis Surgery. Cochrane Database of Systematic Reviews, CD003678.

[20] Hidaka, T., Nakashima, A., Hashimoto, Y. and Saito, S. (2012) Effects of Laparoscopic Radical Surgery for Deep Endometriosis on Endometriosis-Related Pelvic Pain. Minimally Invasive Therapy \& Allied Technologies, 21, 355-361.

https://doi.org/10.3109/13645706.2011.617758 
[21] Seracchioli, R., Mabrouk, M., Frasca, C., Manuzzi, L., Montanari, G., Keramyda, A., et al. (2010) Long-Term Cyclic and Continuous Oral Contraceptive Therapy and Endometrioma Recurrence: A Randomized Controlled Trial. Fertility and Sterility, 93, 52-56. https://doi.org/10.1016/j.fertnstert.2008.09.052

[22] Takamura, M., Koga, K., Osuga, Y., Takemura, Y., Hamasaki, K., Hirota, Y., et al. (2009) Post-Operative Oral Contraceptive Use Reduces the Risk of Ovarian Endometrioma Recurrence after Laparoscopic Excision. Human Reproduction, 24, 3042-3048. https://doi.org/10.1093/humrep/dep297

[23] Jee, B.C., Lee, J.Y., Suh, C.S., Kim, S.H., Choi, Y.M. and Moon, S.Y. (2009) Impact of Gnrh Agonist Treatment on Recurrence of Ovarian Endometriomas after Conservative Laparoscopic Surgery. Fertility and Sterility, 91, 40-45. https://doi.org/10.1016/j.fertnstert.2007.11.027

[24] Canis, M., Donnez, J.G., Guzick, D.S., Halme, J.K., Rock, J.A., Schenken, R.S., et al. (1997) Revised American Society for Reproductive Medicine Classification of Endometriosis: 1996. Fertility and Sterility, 67, 817-821. https://doi.org/10.1016/S0015-0282(97)81391-X

[25] Crosignani, P.G., Vercellini, P., Biffignandi, F., Costantini, W., Cortesi, I. and Imparato, E. (1996) Laparoscopy versus Laparotomy in Conservative Surgical Treatment for Severe Endometriosis. Fertility and Sterility, 66, 706-711. https://doi.org/10.1016/S0015-0282(16)58622-1

[26] Jacobson, T.Z., Duffy, J.M., Barlow, D., Farquhar, C., Koninckx, P.R. and Olive, D. (2010) Laparoscopic Surgery for Subfertility Associated with Endometriosis. Cochrane Database of Systematic Reviews, CD001398. https://doi.org/10.1002/14651858.cd001398.pub2

[27] Sutton, C.J., Ewen, S.P., Whitelaw, N. and Haines, P. (1994) Prospective, Randomized, Double-Blind, Controlled Trial of Laser Laparoscopy in the Treatment of Pelvic Pain Associated with Minimal, Mild, and Moderate Endometriosis. Fertility and Sterility, 62, 696-700. https://doi.org/10.1016/S0015-0282(16)56990-8

[28] Alborzi, S., Momtahan, M., Parsanezhad, M.E., Dehbashi, S., Zolghadri, J. and Alborzi, S. (2004) A Prospective, Randomized Study Comparing Laparoscopic Ovarian Cystectomy Versus Fenestration and Coagulation in Patients with Endometriomas. Fertility and Sterility, 82, 1633-1637. https://doi.org/10.1016/j.fertnstert.2004.04.067

[29] Beretta, P., Franchi, M., Ghezzi, F., Busacca, M., Zupi, E. and Bolis, P. (1998) Randomized Clinical Trial of Two Laparoscopic Treatments of Endometriomas: Cystectomy versus Drainage and Coagulation. Fertility and Sterility, 70, 1176-1180. https://doi.org/10.1016/S0015-0282(98)00385-9

[30] Mossa, B., Ebano, V., Tucci, S., Rega, C., Dolce, E., Frega, A., et al. (2010) Laparoscopic Surgery for the Management of Ovarian Endometriomas. Medical Science Monitor, 16, MT45-MT50.

[31] Al Kadri, H., Hassan, S., Al-Fozan, H.M. and Hajeer, A. (2009) Hormone Therapy for Endometriosis and Surgical Menopause. Cochrane Database of Systematic Reviews, CD005997.

[32] Ball, E., Koh, C., Janik, G. and Davis, C. (2008) Gynaecological Laparoscopy: "See and Treat" Should Be the Gold Standard. Current Opinion in Obstetrics and Gynecology, 20, 325-330. https://doi.org/10.1097/GCO.0b013e32830002bb

[33] Coccia, M.E., Rizzello, F., Cammilli, F., Bracco, G.L. and Scarselli, G. (2008) Endometriosis and Infertility: Surgery and Art: An Integrated Approach for Successful Management. $E u$ ropean Journal of Obstetrics \& Gynecology and Reproductive Biology, 138, 54-59. https://doi.org/10.1016/j.ejogrb.2007.11.010

[34] Tsoumpou, I., Kyrgiou, M., Gelbaya, T.A. and Nardo, L.G. (2009) The Effect of Surgical Treatment for Endometrioma on in Vitro Fertilization Outcomes: A Systematic Review and Meta-Analysis. Fertility and Sterility, 92, 75-87. 
https://doi.org/10.1016/j.fertnstert.2008.05.049

[35] Busacca, M., Olive, D.L., Gomel, V. and Brill, A. (2010) Treatment of Endometriosis Associated Infertility. In: Gomel, V. and Brill, A., Eds., Reconstructive and Reproductive Surgery in Gynecology, CRC Press, Boca Raton, 84-96. https://doi.org/10.3109/9781841847573-10

[36] Vercellini, P., Somigliana, E., Viganò, P., Abbiati, A., Barbara, G. and Crosignani, P.G. (2009) Surgery for Endometriosis-Associated Infertility: A Pragmatic Approach. Human Reproduction, 24, 254-269. https://doi.org/10.1093/humrep/den379

[37] Tang, Y., Chen, S.-L., Chen, X., He, Y.-X., Ye, D.-S., Guo, W., et al. (2013) Ovarian Damage after Laparoscopic Endometrioma Excision Might Be Related to the Size of Cyst. Fertility and Sterility, 100, 464-469. https://doi.org/10.1016/j.fertnstert.2013.03.033

[38] Coric, M., Barisic, D., Pavicic, D., Karadza, M. and Banovic, M. (2011) Electrocoagulation versus Suture after Laparoscopic Stripping of Ovarian Endometriomas Assessed by Antral Follicle Count: Preliminary Results of Randomized Clinical Trial. Archives of Gynecology and Obstetrics, 283, 373-378. https://doi.org/10.1007/s00404-010-1676-x

[39] Busacca, M., Somigliana, E., Bianchi, S., De Marinis, S., Calia, C., Candiani, M., et al. (2001) Post-Operative Gnrh Analogue Treatment after Conservative Surgery for Symptomatic Endometriosis Stage III-IV: A Randomized Controlled Trial. Human Reproduction, 16, 2399-2402.

[40] Jee, B.C., Lee, J.Y., Suh, C.S., Kim, S.H., Choi, Y.M. and Moon, S.Y. (2009) Impact of Gnrh Agonist Treatment on Recurrence of Ovarian Endometriomas after Conservative Laparoscopic Surgery. Fertility and Sterility, 91, 40-45.

https://doi.org/10.1016/j.fertnstert.2007.11.027

[41] Koga, K., Osuga, Y., Takemura, Y., Takamura, M. and Taketani, Y. (2012) Recurrence of Endometrioma after Laparoscopic Excision and Its Prevention by Medical Management. Frontiers in Bioscience, 5, 676-683.

Submit or recommend next manuscript to SCIRP and we will provide best service for you:

Accepting pre-submission inquiries through Email, Facebook, LinkedIn, Twitter, etc. A wide selection of journals (inclusive of 9 subjects, more than 200 journals)

Providing 24-hour high-quality service

User-friendly online submission system

Fair and swift peer-review system

Efficient typesetting and proofreading procedure

Display of the result of downloads and visits, as well as the number of cited articles

Maximum dissemination of your research work

Submit your manuscript at: http://papersubmission.scirp.org/

Or contact ojog@scirp.org 